\title{
Open Port Probe Sampling Interface for the Direct Coupling of Bio- compatible Solid-Phase Microextraction to Atmospheric Pressure Ionization Mass Spectrometry
}

\author{
Germán Augusto Gómez-Ríos ${ }^{ \pm \ddagger}$, Chang Liu**¥, Marcos Tascon ${ }^{ \pm}$, Nathaly Reyes-Garcés ${ }^{ \pm}$, Don W. Ar- \\ nold $^{\S}$, Thomas R. Covey ${ }^{\ddagger}$, Janusz Pawliszyn* ${ }^{ \pm}$ \\ ${ }^{ \pm}$Department of Chemistry, University of Waterloo, Waterloo, Ontario N2L 3G1, Canada \\ ${ }^{\ddagger}$ SCIEX, 71 Four Valley Drive, Concord, Ontario L4K 4V8, Canada \\ ${ }^{\S}$ SCIEX, 1201 Radio Road, Redwood City, CA 94065
}

\begin{abstract}
In recent years, the direct coupling of Solid Phase Microextraction (SPME) and mass spectrometry (MS) has shown its great potential to improve limits of quantitation, accelerate analysis throughput, and diminish potential matrix effects when compared to direct injection to MS. In this study, we introduce the open port probe (OPP) as a robust interface to couple biocompatible SPME (Bio-SPME) fibers to MS systems for direct electrospray ionization. The presented design consisted of minimal alterations to the front-end of the instrument, and provided better sensitivity, simplicity, speed, wider compound coverage, and high-throughput in comparison to the LC-MS based approach. Quantitative determination of clenbuterol, fentanyl, and buprenorphine was successfully achieved in human urine. Despite the use of short extraction/desorption times $(5 \mathrm{~min} / 5 \mathrm{~s})$, limits of quantitation below the minimum required performance levels (MRPL) set by the world anti-doping agency (WADA) were obtained with good accuracy ( $\geq 90 \%)$ and linearity $\left(R^{2}>0.99\right)$ over the range evaluated for all analytes using sample volumes of $300 \mu \mathrm{L}$. In-line technologies such as multiple reaction monitoring with multistage fragmentation $\left(\mathrm{MRM}^{3}\right)$ and differential mobility spectrometry (DMS) were used to enhance the selectivity of the method without compromising analysis speed. Based on calculations, once coupled to high throughput, this method can potentially yield preparation times as low as 15 seconds per sample based on the 96-well plate format. Our results demonstrated that Bio-SPME-OPP-MS efficiently integrates sampling/sample clean-up and atmospheric pressure ionization, making it an advantageous configuration for several bioanalytical applications, including doping in sports, in-vivo tissue sampling, and therapeutic drug monitoring.
\end{abstract}

Within the last twenty years, different strategies aimed at direct and efficient coupling of Solid Phase Microextraction (SPME) devices to mass spectrometry (MS) instrumentation have been explored for analysis of a broad range of matrices with high relevance in clinical, forensic, environmental, and food analysis. ${ }^{1-8}$ To date, most reported direct couplings of SPME fibers are based on work performed either by Górecki et al ${ }^{6,7}$ ("classical" thermal desorption used in gas-chromatography, ${ }^{9,10}$ ) or by Chen et al. ${ }^{11}$ (solvent desorption, suitable for thermally labile compounds). In the latter, the desorption of extracted/enriched analytes occurs by placing the fiber on a desorption chamber (e.g. port, valve, or syringe),${ }^{12-16}$ filled with a solvent with high affinity for the analytes of interest, prior to the atmospheric pressure ionization event (either electrospray ionization (ESI) or atmospheric pressure chemical ionization (APCI)). Aiming to take full advantage of the molar fraction enrichment offered by SPME, ${ }^{4}$ two of our recently reported endeavours applied the methodology initially proposed by Walles et al., ${ }^{5}$ where nano-electrospray ionization (nano-ESI) is used in combination with biocompatible-SPME (Bio-SPME) fibers/tips for fast quantitation of target analytes extracted from biofluids. ${ }^{1,4}$ Although the combination of SPME with nano-ESI is fundamentally "ideal" for analysis of known/unknown substances from complex matrices, in that it yields high ionization efficiency ${ }^{17}$ with minimal solvent consumption and long spray events that allow for numerous MS and $\mathrm{MS}^{\mathrm{n}}$ experiments, ${ }^{18,19}$ drawbacks of this coupling should also be considered in the development of further analytical applications. First, poorly wettable coatings, such as C18-coated fibers, ${ }^{20,21}$ have been found to be capable of generating bubbles inside the nano-ESI emitter (i.e. 'ambient-air' collected inside the particles is released when immersed onto the desorption solvent), which may possibly distort the Taylor-cone formation and, consequently, the electrospray ionization process. Second, the high cost per analysis (i.e. due to the non-reusability of the emitters), as well as the difficulties associated with automatization of the process are additional factors that could thwart the high-throughput implementation of SPME-nano-ESI. Aiming to solve the aforementioned concerns, this manuscript introduces the open port probe (OPP) sampling interface ${ }^{22}$ as a novel, robust, sensitive, and ready-to-use interface for the direct coupling of Bio-SPME fibers to mass spectrometry. As a proof-of-concept, SPME-OPP is herein reported for the first time for determination of controlled substances in relevant clinical assays for urine: treatment of opioid-dependence (i.e. buprenorphine), pain management (i.e. fentanyl), and doping control (i.e. clenbuterol). Given that chromatography can be circumvented by using SPME-OPP, $\mathrm{MRM}^{3}$ or $\mathrm{DMS}^{23-25}$ were implemented to enhance compound selectivity while keeping with the speed and simplicity of traditional MS/MS analysis.

\section{EXPERIMENTAL SECTION}

Materials and Supplies The following compounds were selected as model analytes to evaluate Bio-SPME-OPP: clenbuterol, fentanyl, and buprenorphine. Deuterated analogues of each analyte were used for correction of intra- and inter-experiment variability. Further details regarding compound suppliers, properties, multiple reaction monitoring (MRM), $\mathrm{MRM}^{3}$ transitions, and DMS parameter settings are provided in Table $\mathrm{S} 1$ and S2 of the supplementary information. All LC-MS grade solvents (acetonitrile, methanol, and water) used in experiments purchased from Fisher Scientific (Bartlesville, OK, USA). 


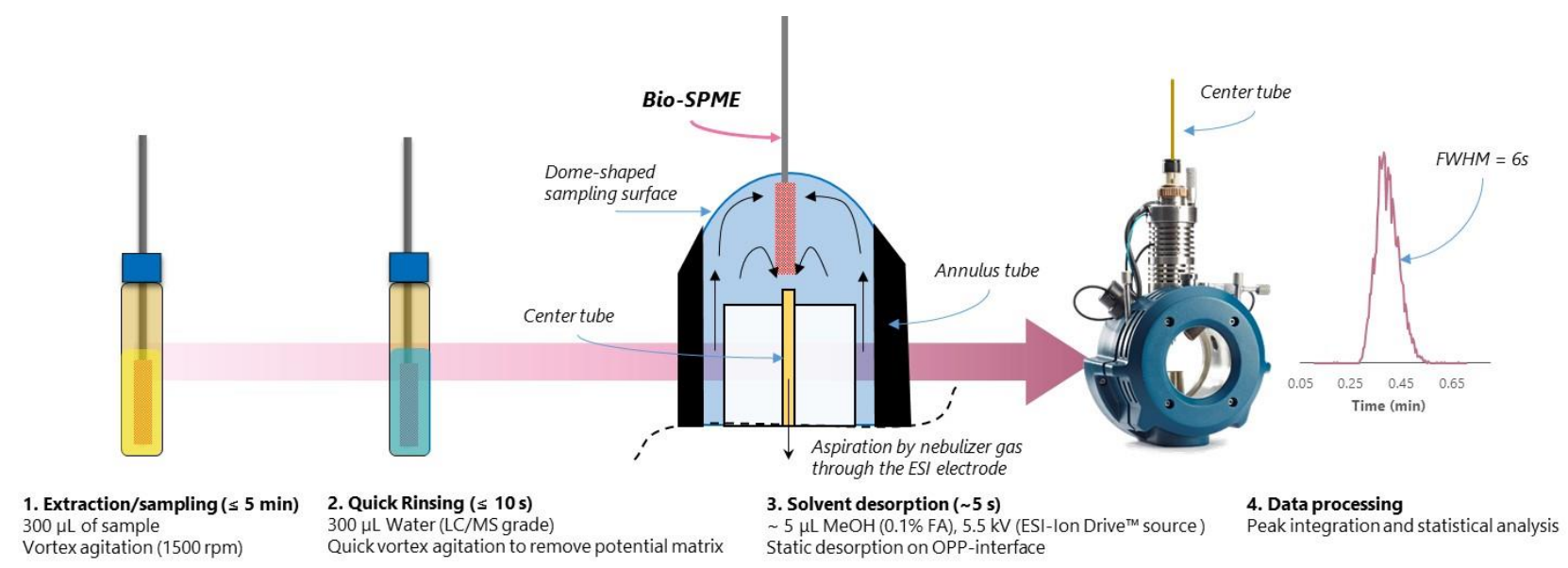

Figure 1 Experimental set-up for Bio-SPME extraction from complex matrices and desorption-ionization via OPP.

Biocompatible SPME mixed-mode probes (i.e. $\mathrm{C}_{18}$-SCX particles, $45 \mu \mathrm{m}$ thickness, $4 \mathrm{~mm}$ coating length) were kindly provided by Supelco (Bellefonte, PA, USA). Although non-biocompatible SPME devices could also be interfaced to OPP, the present work exclusively focuses on bioanalytical applications where the use of biocompatible devices is essential. ${ }^{1}$ Urine samples were collected from six healthy volunteers (three female and three male). Collection of urine from healthy volunteers for this particular study was under the approval of the Office of Research Ethical Board of University of Waterloo.

DMS-MS system An SCIEX QTRAP ${ }^{\circledR}$ 6500+ MS/MS system consisted of Ion Drive ${ }^{\mathrm{TM}}$ source and Electrospray Ionization (ESI) probe, and equipped with the SelexION+ technology, was used in this study. For all DMS analyses, nitrogen was used as the transport gas. Further experimental details regarding the DMS experimental set-up can be found on Section S1 in the Supplementary Information.

Open-Port-Probe (OPP) sampling interface As shown on Figure S1, the OPP sampling interface used in our experiments is similar to the one reported by Van Berkel and collaborators. ${ }^{22,26}$ It is composed of a vertically aligned co-axial tube arrangement that enables solvent delivery to the sampling end through the tubing annulus (304 stainless steel, $1.75 \mathrm{~mm}$ i.d. $\times$ $3.18 \mathrm{~mm}$ o.d. $\times \sim 9 \mathrm{~cm}$ long; Grainger, Lake Forest, IL, USA), and aspiration down the center tube (capillary tube; $254 \mu \mathrm{m}$ i.d. x $361 \mu \mathrm{m}$ o.d. $\times \sim 25 \mathrm{~cm}$ long; Upchurch Scientific, Oak Harbor, WA, USA) into the Ion Drive ${ }^{\mathrm{TM}}$ source driven by the nebulizer gas. ${ }^{22}$ Each tube was secured within a PEEK Tee (Upchurch Scientific, Oak Harbor, WA, USA) so that solvent could be delivered by a solvent pump (200 Series; Perkin Elmer, Santa Clara, CA, USA). The aspiration force through the inner tube of the sampling probe was controlled by the flow rate of the nebulizing gas (nitrogen) into the ion source (90 psi), and the rate of the flow-in solvent was adjusted to achieve a domeshaped sampling surface to maximize the contact area with SPME coatings $(200 \mu \mathrm{L} / \mathrm{min})$. The standard ESI electrode (100 $\mu \mathrm{m}$ i.d.) was replaced by one of equivalent length but with 150 $\mu \mathrm{m}$ i.d. to increase the accessible self-aspiration flow rate range of the system ${ }^{22}$. Positive ion mode ESI was used with ion source nitrogen gas settings GS1 $=90, \mathrm{GS} 2=70$; curtain gas $=25$; heated nebulizer temperature $=350{ }^{\circ} \mathrm{C}$; and electrospray voltage $=5500 \mathrm{~V}$.
SPME extraction and desorption/ionization The analytical workflow for SPME-OPP consisted of three simple steps: extraction/pre-concentration, rinsing, and desorption/ionization (Figure 1). First, the coating of the Bio-SPME fiber was preconditioned on a methanol-water (50:50) solution for about thirty minutes prior to analysis as described elsewhere ${ }^{27}$. Then, the Bio-SPME fiber was inserted in a vial containing the urine sample $\left(\mathrm{V}_{e x t} \sim 300 \mu \mathrm{L}\right)$, and quick extraction/enrichment of the analytes was performed by agitating the sample at high speed (agitation at $1500 \mathrm{rpm}, \mathrm{t} \leq 5 \mathrm{~min}$ ). Next, the fiber was rinsed in a vial containing $\mathrm{LC} / \mathrm{MS}$ grade water $(\mathrm{t} \leq 10 \mathrm{~s})$ to remove matrix components that could potentially adhere to the coating surface. Finally, analyte desorption was achieved by placing the SPME fiber for 5 seconds into the sampling dome of the OPP, such that it touched the continuous flowing stream. Thus, all the analytes extracted on the SPME fiber were desorbed and moved simultaneously from the open-port section of the probe (Figure 1) to the electrospray needle, where they were ionized via ESI mechanism. However, it is important to clarify that the desorption rate of each compound extracted on the fiber would mostly depend on its affinity for both the desorption solvent and the fiber coating. As shown in Figure 2, typical full width at half maximum (FWHM) occurs within 6 seconds with minimal peak broadening, so a new injection can be theoretically performed every 10-15 seconds. It should be noted that incomplete desorption of analytes was observed under the conditions used in this manuscript (i.e. 80\% eluted in $5 \mathrm{~s}$ ). However, this was not a limitation in obtaining quantitative results, as the calibration functions were constructed on the basis of the signal ratio of the analyte and its isotopologue (A/Is) for twelve concertation levels in three independent replicates covering, in this way, the range between 0.1 and $100 \mathrm{ng} \mathrm{mL}^{-1}$. To determine the accuracy of the method, three validation points were evaluated. Although SPME fibers were used as consumables in this study (single use), it is worth to mention that Bio-SPME fibers can be reused by implementing a cleaning step after the desorption/ionization cycle (i.e. mixture of methanol, isopropanol, and acetonitrile; 50:25:25). According to previous studies by Reyes-Garcés et al. ${ }^{21}$, Souza-Silva et al. ${ }^{28}$, and Musteata et al. ${ }^{29}$, a Bio-SPME device can be reused at least 20 times. However, the reusability of the Bio-SPME fibre would depend on multiple factors (e.g. matrix of interest, effectiveness of the cleaning process, and efficiency of the desorption conditions). Therefore, in applications where fibres might be reused, the cleaning step should be 
carefully optimized according to both the matrix, the chemistry of the coating and its affinity towards the target compound. ${ }^{30}$

\section{RESULTS AND DISCUSSION}

SPME-OPP: a simple, fast, and sensitive coupling Certainly, the greatest advantage of the OPP interface, particularly in comparison to other SPME direct couplings to MS, ${ }^{1,10,15}$ is that it requires no modifications to the conventional ionization source setup employed by most analytical labs, allowing the switch between LC-MS and OPP-MS to be achieved in just a few seconds. Indeed, the OPP herein described can be readily built by any skilled user, using mostly commercially available parts. $^{22}$ In addition, the OPP interface can be easily attached to the ESI/APCI source, and no expertise, other than that posed by an average LC/MS user, is required to operate it. Although a conventional LC pump was used in this study for solvent delivery, due to the low back pressure of the system ( $<30 \mathrm{psi})$, lowcost/back pressure pumps can also be implemented to reduce cost and avoid potential problems associated with high-pressure systems (e.g. leaking, expensive parts). Unlike nano-ESI emitters, ${ }^{1,31,32}$ the OPP interface can be used for a long period of time with negligible inter-analysis carry-over owing to its continuous flowing principle. ${ }^{22}$ In addition, the OPP interface is suitable for multi-SPME-fiber automation ${ }^{33}$ and provides minimal risk of ionization interruption upon insertion of dry-fibers since it operates with large-size electrodes (i.e. 100-150 $\mu \mathrm{m}$ i.d. for ESI/APCI versus 1-2 $\mu \mathrm{m}$ i.d. for nano-ESI emitter; then, accounting for bubble formation). Building upon previous research, ${ }^{22}$ the current study seeks to demonstrate that a noteworthy idea (direct-sample-introduction to MS by OPP) can be remarkably improved by using a sample preparation technology (i.e. Bio-SPME fibers) capable of isolating/enriching target analytes from complex matrices (e.g. biofluids, tissues, food samples) with minimal processing time (i.e. less than 2 minutes for the entire analytical process), and adequate sample clean-up (i.e. minimizing matrix effects and instrument contamination for long-term operation). Succinctly, the SPME-OPP coupling merges two attractive technologies to provide limits of quantitation at the low-part-per-billion level, or even part-per-trillion (depending on the analyte affinity for the coating and its ionization efficiency), in substantially short periods of time. Unlike the Open Probe device developed by Amirav's research group ${ }^{34}$ for rapid coupling to electron ionization mass spectrometry, the OPP sampling interface described in this study was designed for ESI or APCI. Although a triple quadrupole/linear ion trap was used in this study, the OPP system can also be coupled to any other mass analyzers such as single quadrupole, ion-traps, or time-of-flight as recently demonstrated by Van Berkel and collaborators ${ }^{35}$

Determination of controlled substances in urine samples When monitoring controlled substances, such as in applications related to doping in sports, pain management, or abuse of illicit drugs, urine is most often selected as a matrix due to the noninvasive nature of its sample collection, and the large sample volumes available. ${ }^{21}$ However, given the complexity of this matrix, as well as the low amount of parent drug excreted, analytical technologies capable of providing quantitative results in the sub-nanogram per milliliter range are highly desired.
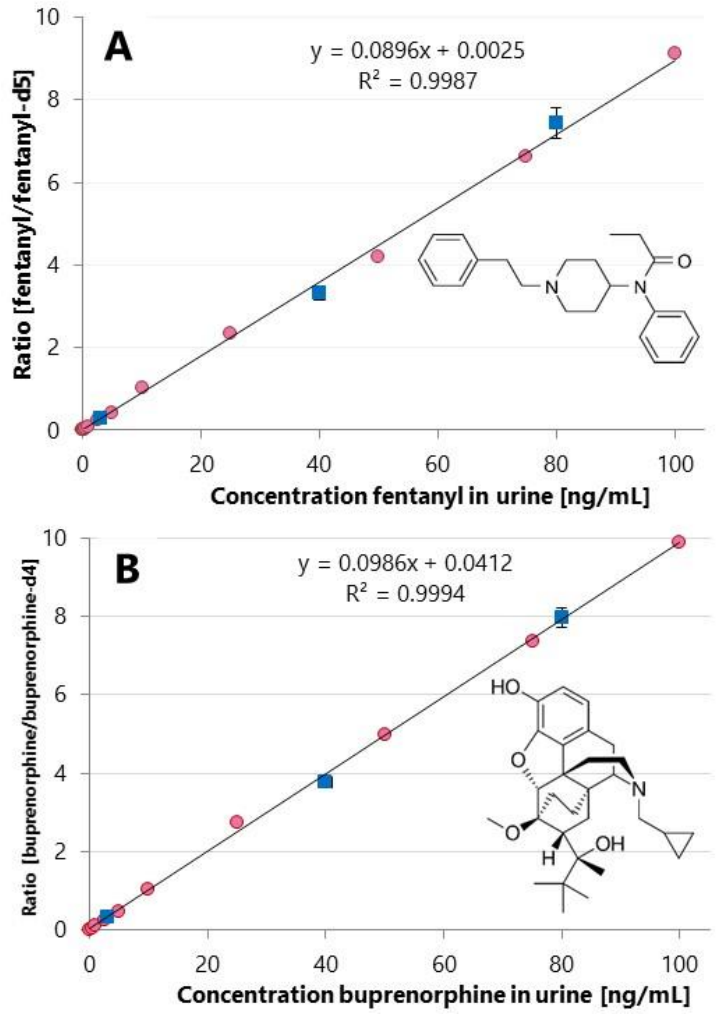

Figure 2. A. Quantitative analysis of urine spiked with fentanyl (50 $\mathrm{pg} \mathrm{ml}^{-1}$ to $100 \mathrm{ng} \mathrm{mL}^{-1}$ ) and its isotopologue [D5] fentanyl $\left(10 \mathrm{ng} \mathrm{mL}^{-1}\right)$. B. Quantitative analysis of urine spiked with buprenorphine $\left(500 \mathrm{pg} \mathrm{ml}^{-1}\right.$ to $\left.100 \mathrm{ng} \mathrm{mL}^{-1}\right)$ and its isotopologue [D4] buprenorphine $\left(10 \mathrm{ng} \mathrm{mL}^{-1}\right)$. Blue squares represent the obtained accuracy levels $\left(3,40\right.$, and $80 \mathrm{ng} \mathrm{mL}^{-1}$, respectively). Bars represent the standard deviation of analyses for three replicates with independent fibers.

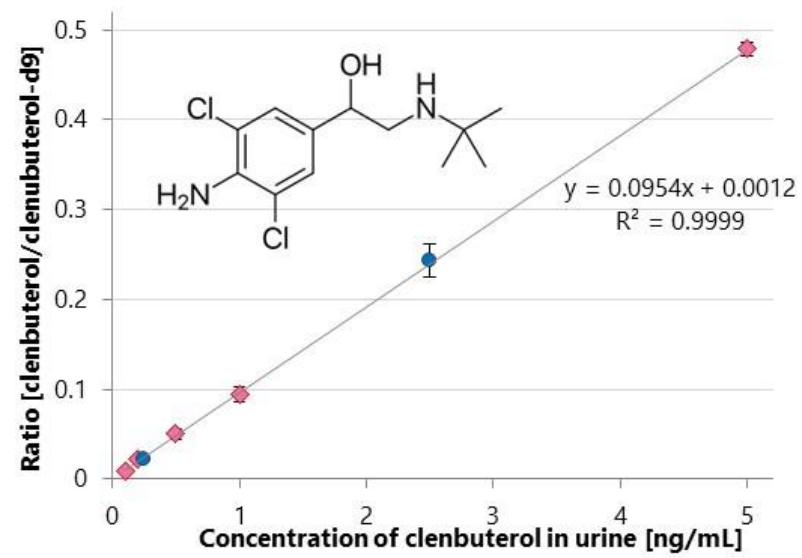

Figure 3. Quantitative analysis of urine spiked with clenbuterol (100 $\mathrm{pg} \mathrm{ml}^{-1}$ to $\left.5 \mathrm{ng} \mathrm{mL}^{-1}\right)$ and its isotopologue [D9] clenbuterol $\left(10 \mathrm{ng} \mathrm{mL}^{-1}\right)$. Analyses were performed using $\mathrm{SPME} \mathrm{OPP}-\mathrm{MRM}^{3}(\mathrm{~m} / \mathrm{z}, 277 \rightarrow 259 \rightarrow 168)$. Blue circles represent the obtained accuracy levels $\left(0.25\right.$ and $2.5 \mathrm{ng} \mathrm{mL}^{-1}$, respectively). Bars represent the standard deviation of analyses for three replicates with independent fibers 
Recently, Reyes-Garcés et al. ${ }^{21,36}$ and Boyacı et al. ${ }^{30}$ demonstrated that different geometrical formats of SPME devices are capable of meeting the Minimum Required Performance Levels (MRPL) set by the World Anti-Doping Agency (WADA) for the analysis of multiple prohibited substances in urine by LCMS. Although SPME-OPP coupling has yet to be perfected, still requiring parameters to be optimized (e.g. ideal fiber-coating thickness, strength of desorption solution, and shape of the open-port that allows for the smallest possible desorption volume), herein we demonstrated that limits of detection (LODs) in the sub-nanogram per millilitre range were achieved for fentanyl and buprenorphine upon performance of 2 min extractions from $300 \mu \mathrm{L}$ of urine (Table S3, Figure S2). In addition, great accuracy (i.e. $93-108 \%$ at 3, 40, and $80 \mathrm{ng} \mathrm{mL}^{-1}$, Figure 2) and linearity were attained for both analytes in the assessed range $\left(\mathrm{R}^{2} \geq 0.9987\right)$. As can be seen in Table S3, our limits of quantitation (LOQ) are certainly below the MRPL values set for fentanyl and buprenorphine in urine $\left(2\right.$ and $5 \mathrm{ng} \mathrm{mL}^{-1}$, respectively ${ }^{30}$ ), which proves the suitability of SPME-OPP-MS/MS for the quantitative determination of controlled substances in human urine.

Unlike fentanyl and buprenorphine, the quantitation of clenbuterol in urine is not a trivial task. ${ }^{21}$ Indeed, in order to reach the required LOQ $\left(0.2 \mathrm{ng} \mathrm{mL} \mathrm{mL}^{-1}\right)$ for this compound, our group demonstrated that chromatographic separation in combination with tandem mass spectrometry are needed for the isolation of matrix interferences co-extracted by the SPME coating. ${ }^{21}$ Although different direct sample-to-MS methods have reported the most abundant transitions $(\mathrm{m} / \mathrm{z}, 277 \rightarrow 259$ or $277 \rightarrow 203)$ for the characterization/quantitation of clenbuterol in complex matrices, ${ }^{37,38}$ our experience has shown that these transitions may lead to false positive results and untrustworthy LOQs (see Figure S3). Thus, aware of the extra challenges provided by the lack of a separation step, $\operatorname{MRM}^{3}(\mathrm{~m} / z, 277 \rightarrow 259 \rightarrow 168)$ was employed to overcome the lack of specificity encountered when exclusively performing MS/MS. ${ }^{39-41}$ As shown in Figure 3, we demonstrated that Bio-SPME-OPP-MRM ${ }^{3}$ can reach a LOQ value of $100 \mathrm{pg} \mathrm{mL}^{-1}$ upon performance of a 5 min extraction from $300 \mu \mathrm{L}$ of urine spiked with clenbuterol (only the lower range of the calibration curve is shown in Figure 3 as to evidence the linearity of the method in this range of concentrations). Furthermore, exceptional linearity in the range of $100 \mathrm{pg}$ $\mathrm{mL}^{-1}$ up to $100 \mathrm{ng} \mathrm{mL} \mathrm{m}^{-1}$ (see Figure $\mathrm{S} 4$, for full-calibration range), and good accuracy (i.e. 82-96\%) at three different levels (i.e. $0.25,2.5$ and $75 \mathrm{ng} \mathrm{mL}^{-1}$ ) were attained (see Table S4, Supplementary Information). Certainly, higher concentration levels are not a limitation. In cases where the affinity of the coating for the analyte is high and analytes are present at con-

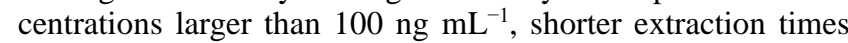
could be employed. It is worth emphasizing that extraction on Bio-SPME fibers can also be performed under static conditions (e.g. during in vivo tissue analysis ${ }^{20}$ ), or at lower speeds of agitation. High-speed agitation was selected in this study with the aim to achieve the required LOQs with minimal total analysis time. $^{2,4}$ In addition to $\mathrm{MRM}^{3}$, it was demonstrated that DMS in combination with MS/MS could also be used for the quantitation of clenbuterol in urine via SPME-OPP. By tuning the adequate compensation voltage $(\mathrm{CoV})$, transmission of the clenbuterol ions through the DMS cell can be achieved while coextracted interferences are deflected. ${ }^{25}$ As shown in Figures S5 and S6, no interference signals were detected and acceptable signal-to-noise ratio at the lowest quality control point tested ( $\mathrm{S} / \mathrm{N} \sim 4.8$ for $0.25 \mathrm{ng} \mathrm{mL}^{-1}$ ) was attained when using DMS.

\section{CONCLUSIONS}

Unquestionably, application of Bio-SPME-OPP has tremendous potential in bioanalytical laboratories for fast determination of therapeutic drugs and prohibited-substances in complex matrices. Its suitability is owed to the multiple advantages it affords, ${ }^{42-44}$ such as the simplicity of the coupling, its aptness for high-throughput analysis (i.e. less than $20 \mathrm{~s}$ per sample when running 96-samples at once), high sensitivity (i.e. sub-ng $\mathrm{mL}^{-1}$ ), and moderate cost per analysis (i.e. reusability of the source and price of each SPME device). ${ }^{21,36}$ Moreover, by using in-line technologies, such MRM ${ }^{3}$ or DMS, enough selectivity enhancement can be achieved, thus making SPME-OPP a much faster alternative to classical LC-MS/MS based approaches. Certainly, the complete quantitation capabilities of SPME-OPP have yet to be discovered. Although this work has been strictly focused on Bio-SPME fibers provided by the commercial vendor, fundamental work on $\mathrm{SPME}^{45}$ has shown that lower LOQ values can be accomplished either by using SPME devices with a larger coated surface area (e.g. blades, mesh, or membranes $3,4,46$ ), increasing extraction time, enhancing the affinity of the coating for the analyte, or consuming larger sample volumes. Consequently, our future work will focus not only on achieving better figures of merit by employing novel SPME geometries amenable to OPP, but also in exploiting the versatility of analytes and matrices that can be analyzed by having ESI/APCI capabilities and DMS integrated into a single source. We foresee the combination of SPME-OPP with robotic platforms for non-assisted time-resolved mass spectrometry applications,${ }^{47}$ as well its implementation for fast determination of exogenous/endogenous compounds extracted in vivo at the surgery room. ${ }^{18}$

\section{ASSOCIATED CONTENT}

\section{Supporting Information}

The supporting information includes the following: materials and supplies; details about MS parameters used to quantify each model compound, and figures of merit for analysis of urine. The Supporting Information is available free of charge on the ACS Publications website.

\section{AUTHOR INFORMATION}

\section{Corresponding Author}

* Phone: +1 (519) 888 4641; Fax: +1 (519) 746 0435. E-mail: janusz@uwaterloo.ca

* Phone: +1 (289) 982 2319; Fax: +1 (905) 660 2623. E-mail:

chang.liu@sciex.com

\section{Author Contributions}

$\$$ These authors contributed equally.

Notes

The authors declare no competing financial interest.

\section{ACKNOWLEDGMENT}

We are grateful to Dr. Yves LeBlanc, Dr. Bradley Schneider, and Dr. Michael Jarvis (SCIEX) for helpful discussions. In addition, we are thankful to our collaborators Dr. Gary Van Berkel and Dr. Vilmos Kertesz at Oak Ridge National Laboratories for their contribution to the development of the OPP. The authors thank SCIEX and the Natural Sciences and Engineering Research Council (NSERC) of Canada for the financial support through an Industrial Research Chair program, and Supelco for kindly providing the SPME fibers used in this study. 


\section{REFERENCES}

(1) Gómez-Ríos, G. A.; Reyes-Garcés, N.; Bojko, B.; Pawliszyn, J. Anal. Chem. 2016, 88 (2), 1259-1265.

(2) Gómez-Ríos, G. A.; Pawliszyn, J. Angew. Chemie 2014, 53 (52), 14503-14507.

(3) Gómez-Ríos, G. A.; Pawliszyn, J. Chem. Commun. 2014, 50 (85), 12937-12940.

(4) Piri-Moghadam, H.; Ahmadi, F.; Gómez-Ríos, G. A.; Boyacı, E.; Reyes-Garcés, N.; Aghakhani, A.; Bojko, B.; Pawliszyn, J. Angew. Chemie 2016, 55 (26), 7510-7514.

(5) Walles, M.; Gu, Y.; Dartiguenave, C.; Musteata, F. M.; Waldron, K.; Lubda, D.; Pawliszyn, J. J. Chromatogr. A 2005, 1067 (1-2), 197-205.

(6) Guo, F.; Górecki, T.; Irish, D.; Pawliszyn, J. Anal. Commun. 1996, 33 (10), 361.

(7) Górecki, T.; Pawliszyn, J.; Belkin, M.; Caruso, J. Anal. Commun 1997, 34 (10), 275-278.

(8) Fang, L.; Deng, J.; Yang, Y.; Wang, X.; Chen, B.; Liu, H.; Zhou, H.; Ouyang, G.; Luan, T. TrAC Trends Anal. Chem. 2016, 85, 6172.

(9) Boyacı, E.; Goryński, K.; Viteri, C. R.; Pawliszyn, J. J. Chromatogr. A 2016, 1436, 51-58.

(10) Mirabelli, M. F.; Wolf, J.-C.; Zenobi, R. Anal. Chem. 2016, 88 (14), 7252-7258.

(11) Chen, J.; Pawliszyn, J. B. Anal. Chem. 1995, 67 (15), 2530-2533

(12) Möder, M.; Löster, H.; Herzschuh, R.; Popp, P. J. Mass Spectrom 1997, 32 (11), 1195-1204.

(13) McCooeye, M. A.; Mester, Z.; Ells, B.; Barnett, D. A.; Purves, R. W.; Guevremont, R. Anal. Chem. 2002, 74 (13), 3071-3075.

(14) van Hout, M. W. J.; Jas, V.; Niederländer, H. A. G.; de Zeeuw, R. A.; de Jong, G. J. Analyst 2002, 127 (3), 355-359.

(15) Ahmad, S.; Tucker, M.; Spooner, N.; Murnane, D.; Gerhard, U. Anal. Chem. 2015, 87 (1), 754-759.

(16) Piri-Moghadam, H.; Lendor, S.; Pawliszyn, J. Anal. Chem. 2016, 88 (24), 12188-12195.

(17) Needham, S. R.; Valaskovic, G. A. Bioanalysis 2015, 7 (9), 1061-1064.

(18) St John, E. R.; Rossi, M.; Pruski, P.; Darzi, A.; Takats, Z. TrAC Trends Anal. Chem. 2016, 85, 2-9.

(19) Li, A.; Hollerbach, A.; Luo, Q.; Cooks, R. G. Angew. Chemie 2015, 54 (23), 6893-6895.

(20) Souza-Silva, É. A.; Reyes-Garcés, N.; Gómez-Ríos, G. A.; Boyacı, E.; Bojko, B.; Pawliszyn, J. TrAC Trends Anal. Chem. 2015, 71, 249-264.

(21) Reyes-Garcés, N.; Bojko, B.; Hein, D.; Pawliszyn, J. Anal. Chem. 2015, 87 (19), 9722-9730.

(22) Van Berkel, G. J.; Kertesz, V. Rapid Commun. Mass Spectrom. 2015, 29 (19), 1749-1756.

(23) Liu, C.; Le Blanc, Y.; Shields, J.; Janiszewki, J.; Ieritano, C.; Ye, G.; Hawes, G.; Hopkins, S.; Campbell, J. L. Analyst 2015, 140
(20), 6897-6903

Chouinard, C. D.; Wei, M. S.; Beekman, C. R.; Kemperman, R. H. J.; Yost, R. A. Clin. Chem. 2016, 62 (1), 124-133.

Schneider, B. B.; Nazarov, E. G.; Londry, F.; Vouros, P.; Covey, T. R. Mass Spectrometry Reviews. May 2016, pp 687-737.

Van Berkel, G. J.; Kertesz, V. Rapid Commun. Mass Spectrom. 2016.

Reyes-Garcés, N.; Bojko, B.; Hein, D.; Pawliszyn, J. Anal. Chem. 2015, 87 (19), 9722-9730.

Souza Silva, É. A.; Pawliszyn, J. Anal. Chem. 2012, 84 (16) 6933-6938

Musteata, M. L.; Musteata, F. M.; Pawliszyn, J. Anal. Chem. 2007, 79 (18), 6903-6911.

Boyacı, E.; Gorynski, K.; Rodriguez-Lafuente, A.; Bojko, B.; Pawliszyn, J. Anal. Chim. Acta 2014, 809, 69-81.

Zhao, Y.; Gong, X.; Si, X.; Wei, Z.; Yang, C.; Zhang, S.; Zhang, X. Analyst 2015, 140 (8), 2599-2602.

Deng, J.; Yang, Y.; Xu, M.; Wang, X.; Lin, L.; Yao, Z.-P.; Luan, T. Anal. Chem. 2015, 87 (19), 9923-9930.

Gómez-Ríos, G. A.; Reyes-Garcés, N.; Pawliszyn, J. J. Sep. Sci. 2015, 38 (20), 3560-3567.

Poliak, M.; Gordin, A.; Amirav, A. Anal. Chem. 2010, 82 (13) 5777-5782.

Van Berkel, G. J.; Kertesz, V. Rapid Commun. Mass Spectrom. 2016.

Reyes-Garcés, N.; Bojko, B.; Pawliszyn, J. J. Chromatogr. A 2014, 1374, 40-49.

Zhang, Z.; Cooks, R. G.; Ouyang, Z. Analyst 2012, 137 (11) 2556-2558.

Ren, Y.; Liu, J.; Li, L.; McLuckey, M. N.; Ouyang, Z. Anal. Methods 2013, 5 (23), 6686-6692.

, Z.; Zhang, S.; Zhao, M.; Yang, C.; Chen, D.; Zhang, X. Rapid Commun. Mass Spectrom. 2008, 22 (12), 1882-1888.

Guddat, S.; Fußhöller, G.; Geyer, H.; Thomas, A.; Braun, H.; Haenelt, N.; Schwenke, A.; Klose, C.; Thevis, M.; Schänzer, W. Drug Test. Anal. 2012, 4 (6), 534-538.

Snyder, D. T.; Fedick, P. W.; Cooks, R. G. Anal. Chem. 2016, 88 (19), 9572-9581

Anizan, S.; Huestis, M. A. Clin. Chem. 2014, 60 (2), 307-322.

Thevis, M.; Kuuranne, T.; Walpurgis, K.; Geyer, H.; Schänzer, W. Drug Test. Anal. 2016, 8 (1), 7-29.

Ferreira, C. R.; Yannell, K. E.; Jarmusch, A. K.; Pirro, V.; Ouyang, Z.; Cooks, R. G. Clin. Chem. 2015, 62 (1), 99-110.

Alam, M. N.; Ricardez-Sandoval, L.; Pawliszyn, J. Anal. Chem. 2015, 87 (19), 9846-9854.

Grandy, J. J.; Boyacı, E.; Pawliszyn, J. Anal. Chem. 2016, 88 (3), 1760-1767.

Chiu, S.-H.; Urban, P. L. Biosens. Bioelectron. 2015, 64, 260268. 
Table of Contents (TOC) graphic:

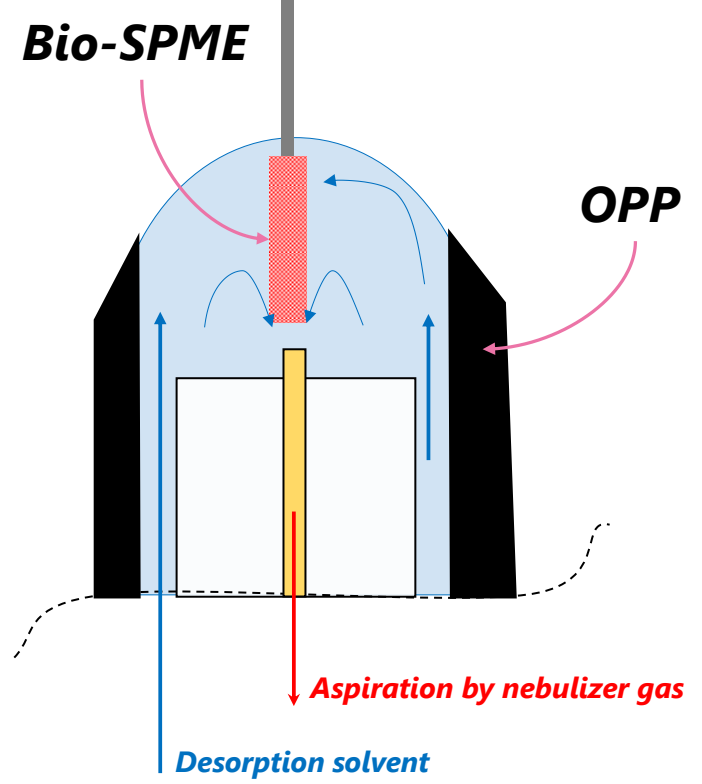

